\title{
Living, and living well, after cardiac surgery
}

\author{
Masahiko Ando, MD, PhD, MPH, ${ }^{\mathrm{a}}$ Jonathan Hastie, MD, ${ }^{\mathrm{b}}$ and Hiroo Takayama, MD, $\mathrm{PhD}^{\mathrm{a}}$
}

\author{
From the ${ }^{\mathrm{a} D i v i s i o n}$ of Cardiothoracic and Vascular Surgery and ${ }^{\mathrm{b}}$ Department of Anesthesiology, Columbia Uni- \\ versity Medical Center, New York, NY. \\ Disclosures: Authors have nothing to disclose with regard to commercial support. \\ Received for publication May 24, 2018; revisions received May 24, 2018; accepted for publication May 30, 2018; \\ available ahead of print July 20, 2018. \\ Address for reprints: Hiroo Takayama, MD, PhD, Division of Cardiothoracic and Vascular Surgery, Columbia \\ University Medical Center, 177 Ft Washington Ave, New York, NY 10019 (E-mail: ht2225@cumc. \\ columbia.ed). \\ J Thorac Cardiovasc Surg 2018;156:1905 \\ $0022-5223 / \$ 36.00$ \\ Copyright (C 2018 by The American Association for Thoracic Surgery \\ https://doi.org/10.1016/j.jtcvs.2018.05.121
}

Improved survival after cardiac surgery in the current era ${ }^{1}$ has allowed the focus to shift toward patients' quality of life (QoL). This metric is particularly important for the growing proportion of patients with advanced age, and yet the question of how to improve and maintain QoL suffers from a dearth of literature in our field. ${ }^{2}$

Diab and colleagues' work ${ }^{3}$ - highlighted in this issue of the Journal—offers significant insight into the recovery of patients after cardiac surgery, and for this they are to be commended. This prospective, observational study characterized outcome differences at 6 months and 1 year between those who stayed in the intensive care unit (ICU) 2 days or less and those who required 3 or more days of critical care (Norm ICU and Long ICU groups, respectively).

There are several salient points for the clinician. First, the study confirms the intuition that Long ICU patients have worse postoperative morbidity and mortality than Norm ICU patients. Unsurprisingly, these patients also have increased preoperative illness. These data will provide better grounding for both care providers' and patients' expectations and communication. Second, the trajectory of continued recovery at 1 year is reassuring; those with a prolonged ICU course may continue to improve. Third, the quality of recovery, defined as a return to baseline function among various domains, was significantly worse at 12 months in the Long ICU group than in the Norm ICU group. These patients had a significantly slower rate of improvement in the domains of emotive recovery, cognitive recovery, and activities of daily living. It should be noted, however, that fewer than $80 \%$ achieved a return to baseline function even in the Norm ICU group.

When interpreting these results, one is constantly reminded that "dead patients do not complain." The concern for overestimation of QoL in Long ICU patients as a result

\section{References} 2018;156:1906-15. Outcomes. 2014;12:62.

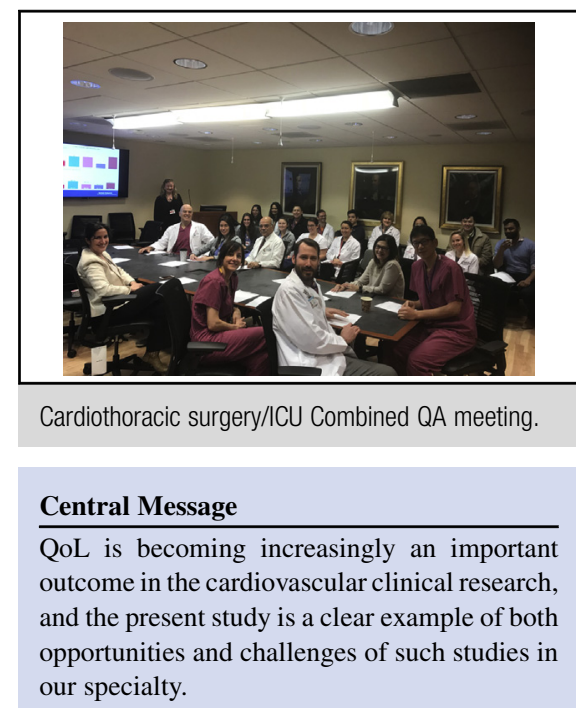

See Article page 1906.

of dropouts, especially among elderly patients, has been raised. ${ }^{4}$ Despite the gradual recovery in QoL in Long ICU patients, these patients demonstrated significantly worse survival, with a reduced rate of follow-up (82.6 vs $94.4 \%$ ). Although statistical methods may aim to account for the impact of mortality on the analysis, only a patient can assess QoL in light of his or her values and goals. Softer-yet meaningful—end points such as QoL are becoming increasingly important in cardiovascular clinical research, and this study of Diab and colleagues ${ }^{3}$ provides a clear example of both opportunities and challenges of such studies in our specialty.

1. McNeely C, Markwell S, Vassileva C. Trends in patient characteristics and outcomes of coronary artery bypass grafting in the 2000 to 2012 medicare population. Ann Thorac Surg. 2016;102:132-8.

2. Noyez L, de Jager MJ, Markou AL. Quality of life after cardiac surgery: underresearched research. Interact Cardiovasc Thorac Surg. 2011;13:511-4.

3. Diab MS, Bilkhu R, Soppa G, Edsell M, Fletcher N, Heiberg J, et al. The influence of prolonged intensive care stay on quality of life, recovery, and clinical outcomes following cardiac surgery: a prospective cohort study. J Thorac Cardiovasc Surg.

4. Noyez L. Is quality of life post cardiac surgery overestimated? Health Qual Life 